\title{
When Borders Blur - Overcoming Political Limits with Computing in Truly Global Societies
}

\author{
Emmanuel Azuh Mensah \\ University of Washington \\ emazuh@cs.washington.edu \\ Richard Anderson \\ University of Washington \\ anderson@cs.washington.edu
}

\author{
Sudheesh Singanamalla \\ University of Washington \\ sudheesh@cs.washington.edu \\ Kurtis Heimerl \\ University of Washington \\ kheimerl@cs.washington.edu
}

\begin{abstract}
As global conditions cause an increasing need for people to move across borders, current gate-keeping mechanisms (e.g. the visa process) make such movements extremely difficult. While it's understandable that governments want to maintain security within their countries, it is possible for displaced people to contribute economically to development in the destination countries. Even though a completely borderless world of governments would be difficult to achieve, we argue that governments can combine policy with technology to remove barriers to potential growth from migrants, while maintaining security. In this paper, we sketch an interoperable digital government identity and automatic verification systems aimed at allowing governance structures while overcoming the limits of human processing in the visa application system in the face of ecological limits.
\end{abstract}

\section{Reference Format:}

Emmanuel Azuh Mensah, Sudheesh Singanamalla, Richard Anderson, and Kurtis Heimerl. 2021. When Borders Blur - Overcoming Political Limits with Computing in Truly Global Societies. In LIMITS '21: Workshop on Computing within Limits, June 14-15, 2021.

\section{INTRODUCTION}

It goes without saying that cross country collaboration has led to many innovations, especially in the most developed countries. These collaborations however are sometimes stifled due to gatekeeping mechanisms such as the visa process. Again, as the effects of climate change worsen, conflict and weather conditions may necessitate the movement of masses in search of new homes inside and outside their countries of origin [36]. The move however, does not mean people cease to be productive. In fact, immigrants usually do a lot of physically and mentally demanding work that society profits from [8]. It is also common for immigrants, especially low income ones to also lose a part of their identity due to a lack of transference in their livelihood to the new country[16]. Tomlinson [42] suggested an immigration assistant that uses collaborative filtering to match migrants with particular sets of skills and interests with destination countries looking for such skills. However, people

Permission to make digital or hard copies of part or all of this work for personal or classroom use is granted without fee provided that copies are not made or distributed for profit or commercial advantage and that copies bear this notice and the full citation on the first page. Copyrights for third-party components of this work must be honored. For all other uses, contact the owner/author(s).

LIMITS '21, fune 14-15, 2021,

(C) 2021 Copyright held by the owner/author(s). who are matched may still be discouraged from traveling due to how difficult and expensive some of the visa applications can be, leading to lots of missed opportunities.

Furthermore, innovations in air travel promise to cut down travel time by orders of magnitude. For example, reusable orbital rocket transportation such as Starship proposes to drastically reduce the time needed for human movement across geographies (e.g. a travel time of 29 minutes to travel between London and New York compared to the 7.5 hours today) [2,33]. Yet such innovations still depend on fossil fuels in order to become a reality. The limited supply of fossil fuels that power such innovations and the lack of more promising energy alternatives at the moment for commercial flights [24] suggest that computing systems used in travel need to be constantly built with sustainability in mind. There is therefore a need to rethink the future of cross country travel, using computing to improve transparency, equity and sustainability.

It is high time we started addressing the limits that politics poses in global human dynamics and enable the use of computing to support global travel policies for instance for displaced populations as well as to improve inter-country collaboration. With the issuance of national identities by 175 countries of which 161 countries issue digital identities for their citizens [6], and the adoption of new open source identity systems like MOSIP [23], governments are constantly exploring the development of foundational national identity systems. In this paper, we aim to address the limits in seamless human mobility due to visa processing inefficiencies by leveraging digital identities and cryptographic techniques.

For the rest of the paper, we describe the current format of the visa processing system, propose a blueprint for an automated visa processing system, and discuss the implications of our systems as viewed through a computational, political and sustainability lens.

\section{BACKGROUND}

Visa processing today experiences significant delays caused mostly by bottlenecks from human processing, limiting people's ability to seek refuge, travel for trade and diplomacy, etc. The Finnish consulate in Russia for instance allows only Finnish citizens, typically a fixed number of employees, who take holidays and other leaves, to make visa decisions for a demand that is seasonal [26]. Many governments use the visa application process as a deterrent for applicants the country determines as a security threat. The side effect however, is that the process deters both welcome and unwelcome applicants due to the strenuous process required, reducing economically beneficial travels to the destination country by an 
average of 52-63 percent [25]. The current methods of keeping migrants out are not only costly but lead to adverse effects such as exacerbation of human trafficking [32]. It is therefore important to create a system that allows legitimate applicants the ease of travel while maintaining security standards.

Governments have recently been discussing organizational readiness of blockchain technologies in e-governance [7, 28], though the countries running Public Key Infrastructure (PKI) is heavily skewed with a disproportionate number of Certificate Authorities (CAs) in the United States [40]. These technologies foreshadow a possible future of secure automated visa processing. Existing credit scoring systems can also provide insight into methods to not only automate the visa verification process but also extend access to underprivileged persons who don't have access to conventional financial credit scores. For example, to get a mortgage for a house in the United States, one would need a credit score [39] estimated based on payment history, length of credit history, etc. that indicates ability to pay back debt. In fact, such scoring systems can tell more about individuals including inferred relations between credit score and health outcomes [19]. Yet these systems have been criticized for historical and racial biases, with many low-income neighborhoods having higher credit invisibility (no credit history with credit reporting agencies) and little information on how to understand and improve credit scores [10]. More inclusive methods for low income citizens such using mobile credit history from Mobile Network Operators (MNOs) [3] in developing countries as well as using agricultural property and outcomes [1] can be extended into a more holistic score to be used across country borders.

\section{UNDERSTANDING CURRENT VISA PROCESSING \& VERIFICATION SYSTEMS}

\subsection{Current Workflows \& Role of Computing}

An individual with the intent to travel for business, or pleasure goes through an application process starting from an online or a paper based system provided by the embassy. The individual fills in information regarding identity (passport), self attests questions regarding marital status, income, education and any criminal proceedings against the individual. Once complete, the applicant attaches copies of necessary financial, medical, travel and legal proofs obtained from various authorities in their country. This process could be time consuming and error prone, leading to phrases such as the "Visa Wahala", which is a popularized term West Africans use to refer to the troubles that the visa application process comes with. For instance, one of the main reasons for the rejection of a US visa application is "Incomplete Application or Missing Supporting Documentations" [4]. If the consular determines they need more financial evidence, it might take twice as long for an applicant to get their visa - a process that already takes a month or more from the start of the visa application process. The dread of the visa application has given rise to various consultancies offering visa assistance services. There is however, no guarantee of how these organizations maintain and process sensitive information regarding the individual applicant, leading to possible identity theft and fraud. Some countries also require an in person interview as a means of information validation and establishing a proof of personhood.

\subsection{Challenges with Current Practices}

Embassies processing visa applications today collect a lot of data without transparent public information about data retention practices. This data is also available to third party organizations that provide services like the background screening, posing a huge risk to privacy in the case of a cyber-attack or data leakage [34].

The visa application process is itself expensive, costing at least 160 USD for the most common non immigrant visa to the United States for example, despite improvements to visa processing to spur economic growth [30,38]. This is higher than the average monthly income of citizens in several countries [13]. Millions of people (including climate and conflict refugees) are thereby restricted from easy movement to improve their livelihoods by seeking work or providing services. People who successfully go through the process also usually don't have a good idea about how their travels contribute to global emissions.

The documentation required is also challenging to obtain for many individuals in various countries due to lack of public infrastructure, the type of government, and corruption. As a proof of income, many visa applications require an attested version of the current value of investments and holdings from banks and income tax filings. Some countries do not have tax structures in place and in some countries the banking structure might differ with mobile or neo-banking (online-only banking) being more heavily used than conventional physical banks. To adapt to this, the visa application process differs heavily based on the country where the individual is requesting the visa.

Additionally, the visa application process is fraught with many inconsistencies and is time consuming due to the nature of security needed. For instance, for some consulates, making a payment with a credit card other than one issued in the country of application can result in a locking of the application which unlocks about two weeks after the application attempt and requires a restarting of the application process [5]. During a more difficult period such as the COVID 19 pandemic, 5-8 months of processing time was added to the visa application process [9].

\section{PROPOSED SOLUTION}

With the understanding of the ecosystem and the challenges in current practices, we propose a solution which aims to achieve various design goals we describe in section 4.1 by making the necessary security assumptions. In the proposal, we detail the various components and public infrastructure for our system.

\subsection{Design Goals}

4.1.1 Security Assumptions. We assume a trusted relationship between the country's citizens (individuals) and the public infrastructure. Each government uses secure networking protocols for any data exchange and communication between stakeholders. Stakeholders are vetted through a one-time process as a part of enabling the user to connect and participate in the secure network.

4.1.2 Guarantees. With the goal to overcome human and political limits in the visa application process with sustainability and inclusion in mind, the proposed system also aims to provide the various stakeholders with guarantees of security, privacy and transparency. 
While the citizens trust their respective governments to maintain the identity information, the proposed system should only allow the consented usage of the individual's information with a transparent trace of all entities who have requested the information. Cross border interactions between government systems need to be secure, with peering countries notified of failures that result in denial of information or tampering of individuals' data.

\subsection{Components of the Proposed System}

In this section, we detail the different components of e-governance and visa issuance infrastructure which form the building blocks of the of our proposed system.

4.2.1 National Public Key \& Signing Infrastructure (NPKI). Each government provides the ability for its citizens to perform digital signatures on any document [27] using identities backed by biometrics. The infrastructure also establishes the certificates for educational, financial and healthcare institutions.

4.2.2 Digital Documents Storage Service. Various stakeholders certified by the NPKI provide signed attestations for an individual, attached to their national identity and made available through a digital documents service such as DigiLocker in India [29]. The service holds both signed metadata and issued documents, which could be made selectively available during automated visa processing.

4.2.3 Global Government Blockchain Network. We propose that organizations within a country interact with various international systems using a blockchain network to establish higher levels of trust with citizens. A blockchain allows participants to create a tamper resistant ledger of transactions that are validated by a consensus mechanism, decentralizing trust among untrusting participants by creating accountability and transparency through collective verifiablity [31].

4.2.4 Local and Global Auditors. It is important to have an ecosystem of global and local auditors who probe various governments for proofs regarding tamper resistance $[11,21]$.

\subsection{Proposed Workflows with New Systems}

A citizen of a country $A$ intending to travel to another country $B$ uses their government issued digital identity indicating the intent. The visa processing system of country $B$ can verify the authenticity of the data presented and verify the root of trust established by the CA of country $A$ using the individual's provided consent. To complete the visa processing, the system requests for financial proofs, education and work information, health (vaccination) records and invitations from sponsors in country $B$. The visa applicant uses their national digital documents storage service to retrieve signed documentation of education, work, etc. Using the verifiable credentials scheme [41], it becomes possible to selectively reveal the information corresponding to attributes such as monthly average balance, or age of credit history without revealing all banking transactions. Using a zero knowledge proof [15], it is further possible for the visa processing system of country $B$ to challenge the delegated stakeholders in country $A$ (banking, identity etc...) to prove the correctness of the data. It is also possible to collect flight history (summary of individual carbon emission contribution) from airline companies. In automating the visa application process, discussions around how consulars determine the applicant's fit for the destination country arises. We propose to use systems such as the financial and social credit systems among others to define a standard but customizable immigration fit score that automatically determines if an applicant is granted a visa based on estimations of financial responsibility, law abiding qualities, etc. Proxy methods such as mobile credit history and work outcomes $[1,3]$ can be considered when conventional scores aren't available. Since MNOs keeping mobile credit history are usually cross country, their storage systems are more likely to survive even in disaster events and so will still be able to provide data on the applicant. AI systems such as improvements on that proposed in [17] can be employed to assess the content of the supporting documents. On successful completion of the application and the ensuing data verification protocols, a cryptographically signed and encrypted response is issued for the individual indicating the approval of the visa. The issued visa token could be stored in e-passports during check-in in the country of departure, printed as a QR code or made available through a secure mobile application.

\subsection{Challenges Addressed}

Citizens are now able to automatically use their digitally issued national identification and identity bound services within the country like banking for completing an application process on demand. With the ability to selectively reveal information, it becomes possible to improve the user privacy across countries. All the interactions with user data are logged in append-only verifiable data stores, providing individuals with detailed trace of data requested by various stakeholders to enable transparency in how data is used. Due to the near real-time processing, the system is able to process many more individuals at the same time, which is useful especially in disaster relief situations, and reduces the exorbitant costs for visa applications. Streamlining the process by involving a digital identity system reduces the number of third party consultants and the probabilities of fraudulent activities that otherwise would result in careless maintenance of personal data. The system now incorporates travelers' carbon footprint as well in making visa decisions. Again, individuals who lack traditional proof of finances are still able to show their work ethic by other means. Finally, applicants who wish to transfer to a similar lifestyle in the destination country can elect to share relevant information during the application process to be used in the match-making algorithm [42].

\section{DISCUSSION}

In this section, we discuss the limits of our system as situated within the limits of the visa processing system.

\subsection{Security \& Privacy - Consented Data Usage}

The current proposal places the citizens' trust in their government and considers non-colluding governments who focus on protecting the privacy and security of their citizens. However, collusion between governments and auditors can result in data being shared without any notification or trace to the citizens. Our argument of security hinged on the fact that governments are trustworthy. However, if a government decides to censor information (eg about 
military status), the destination country would either reject the applicant's visa or accept proxy ways of verifying the applicant's information. Our current system doesn't address such proxy ways. Some possible workarounds would be for government to accept a self declared status along with authoritative proof such as an endorsed letter of admission into the military, etc.

Current implementations of digital national identity systems result in the identity system creating, managing and destroying the keys with the help of trusted hardware execution modules [27] One way to improve security is to provide individuals the ability to generate their own key pair and physically visit a government authority to verify and bind the public key to a national identity. While the keys are now secure with the individual, preventing malicious or compromised government authorities from forging signatures, novice users might face usability challenges, and issues regarding revocation of existing keys and their update in cases of loss or theft of devices.

\subsection{Accessibility, Equality and Inclusion}

We estimate that the reduced human intervention in the application process will lead to a drastic drop in processing fees, thereby allowing people with the need to move between countries. However, biometric systems for authentication that use fingerprints and iris scans to identify individuals might not be inclusive towards people with physical disabilities (e.g. amputations, vision loss). Biometric information such as fingerprints also fade over time for individuals doing hard manual labor and change as children grow into adults requiring the biometric information to be periodically updated and hardware vendors to carefully tune the sensitivity of the biometric devices [14]. Our system ends up allowing governments from different cultures to decide the proper cultural accessory information to share (e.g. whether to present only age instead of date of birth). The transparent nature of the data being requested by countries to make a visa decision can be contested by privacy activists resulting in possible changes to the policies. Finally, the automated visa processing algorithm could have biases that can have serious consequences regarding intended/unintended discrimination against certain groups of individuals [43]. However, there is active and promising ongoing research into algorithmic fairness in automated efforts $[12,18]$.

\subsection{Expectations on Infrastructure}

A potential downside of our proposition is that it expects many infrastructural changes which may take a long while to become a reality. For instance, governments and credit agencies need to actively collect, store and process biometric information about their citizens. They also need to build and maintain security practices for the infrastructure to provide a digital identity system followed by mapping individual's credentials, health, and financial records in a privacy preserving manner. Again, in a global network, any failures in operations could result in significant delays affecting the credibility and trustworthiness of the governments and potentially stalling operations for millions of travelers.

\subsection{Political Limits}

In spite of debates regarding rights to migration [22], governments who decide to trust each other and who are able to rely on the automated immigration scoring function will be able to open their borders to the right people. By governments agreeing on standards to increasing transparency in the visa decision process, individuals can be better informed to prepare themselves as great candidates to live in the destination country. Governments who choose not to be completely transparent can augment the automated system, allowing them a chance to be transparent about certain parts of the decision process. Again, our automated system can make it easier for governments to target activists, immigrants and refugees. A potential way to keep governments accountable is to keep track of country level statistics on the public ledger on information such acceptance/rejection rates of applicants in certain categories (e.g. refugee seeker, activist, etc). As more countries buy into this level of transparency, democratic countries that refuse to allow such metrics to be published make an open statement to the world about where they truly stand.

\subsection{Sustainability}

The usage of blockchain in our proposal could be energy intensive. However, we hope that advances in technology will eventually decrease the energy requirement towards better sustainability [20, 37]. In the limits of low energy supply, the design may have to relax the need for building trust in a decentralized manner and accept the risk of governments tampering with the application process. Success of our proposal would also mean a great rise in travel, which could worsen the effects of climate change [24]. Governments can decide to allow people who truly need to travel to use the full potential of expedited travel. Furthermore, even though this system appears to increase the complexity of society as described in [35], we believe our proposal doesn't cause regression because it extends existing technology (most notably blockchain infrastructure), while proposing a standardized approach to visa decision making. We believe such considerations will allow participating countries to advance in their collaborations with each other for progress.

\section{CONCLUSION}

As we approach ecological limits and worsening global climate conditions, it becomes important to build systems that consider said limits. In this paper, we observe inefficiencies in the visa application process and how they lead to negative consequences for both migrants and the destination countries. We leverage state of the art technology in cryptography along with the potential for governments to collaborate in a deeply global world to propose a blueprint for an inclusive and sustainable automated visa processing system. With our proposed system, we see a potential to significantly cut down on the visa processing time, and therefore bring humans from around the globe closer together for collaboration, exchange of services, provision of security, etc. more than ever before.

\section{ACKNOWLEDGEMENTS}

We would like to thank Barath Raghavan for shepherding the paper and Jay Chen for providing valuable feedback which shaped the final version of the paper. 


\section{REFERENCES}

[1] 2018. DIGITAL FARMER PROFILES: Re-imagining Smallholder Agriculture. https://www.usaid.gov/sites/default/files/documents/15396/Data_Driven_ Agriculture_Farmer_Profile.pdf Accessed: 2021-03-31.

[2] 2020. Preparing for "Earth to Earth" space travel and a competition with supersonic airliners. https:/www.nasaspaceflight.com/2020/12/earth-to-earthsupersonic-airliners/ Accessed: 2021-03-31.

[3] 2021. Data Analytics and Digital Financial Services. https: //www.ifc.org/wps/wcm/connect/369c10de-1703-4497-876f-9cdf0367a4d4/ IFC+Data+Analytics+and+Digital+Financial+Services+Handbook.pdf?MOD= AJPERES\&CVID=lRrkzEd Accessed: 2021-03-31.

[4] 2021. U.S. Department of State Visa Denial. https://travel.state.gov/content/ travel/en/us-visas/visa-information-resources/visa-denials.html Accessed: 202103-29.

[5] A Aheni. 2016. Spain Via London...Let me tell you something!!! Visa Wahala...British/ UK Visa on a Ghanaian Passport. https://aheniblog.wordpress com/2016/09/07/spain-via-london-ukvisa-schengenvisa/\#more-33

[6] The World Bank. 2018. Identification for Development (ID4D) Global Dataset (Global ID4D Database) | Data Catalog. https://datacatalog.worldbank.org/ dataset/identification-development-global-dataset. (Accessed on 04/01/2021).

[7] F Rizal Batubara, Jolien Ubacht, and Marijn Janssen. 2018. Challenges of blockchain technology adoption for e-government: a systematic literature review. In Proceedings of the 19th Annual International Conference on Digital Government Research: Governance in the Data Age. 1-9.

[8] Edna Bonacich. 1987. "Making it" in America: A social evaluation of the ethics of immigrant entrepreneurship. Sociological Perspectives 30, 4 (1987), 446-466.

[9] Boundless. 2020. Coronavirus Immigration FAQ: Information for U.S. Immigrants. https://www.boundless.com/immigration-resources/coronavirusimmigration-faq/. (Accessed on 04/03/2021).

[10] Natalie Campisi. 2021. From Inherent Racial Bias to Incorrect Data-The Problems With Current Credit Scoring Models. https://www.forbes.com/advisor/creditcards/from-inherent-racial-bias-to-incorrect-data-the-problems-withcurrent-credit-scoring-models/. (Accessed on 04/02/2021).

[11] Melissa Chase, Apoorvaa Deshpande, Esha Ghosh, and Harjasleen Malvai. 2019 Seemless: Secure end-to-end encrypted messaging with less trust. In Proceedings of the 2019 ACM SIGSAC conference on computer and communications security. $1639-1656$.

[12] Sam Corbett-Davies, Emma Pierson, Avi Feller, Sharad Goel, and Aziz Huq. 2017. Algorithmic decision making and the cost of fairness. In Proceedings of the $23 \mathrm{rd}$ acm sigkdd international conference on knowledge discovery and data mining. 797-806.

[13] Wold Data. 2018. Average income around the world. https://www.worlddata. info/average-income.php. (Accessed on 04/03/2021).

[14] Bryan Ford. 2020. Identity and Personhood in Digital Democracy: Evaluating Inclusion, Equality, Security, and Privacy in Pseudonym Parties and Other Proofs of Personhood. arXiv preprint arXiv:2011.02412 (2020).

[15] Oded Goldreich and Yair Oren. 1994. Definitions and properties of zeroknowledge proof systems. Journal of Cryptology 7, 1 (1994), 1-32.

[16] Andrea Hartmann. [n.d.]. Losing, transporting and re-claiming identity. ([n. d.]).

[17] Syed I Jami and Zubair A Shaikh. 2018. Semantic Web based E-Government System. Indian fournal of Science and Technology 11 (2018), 44.

[18] Jon Kleinberg, Jens Ludwig, Sendhil Mullainathan, and Ashesh Rambachan. 2018. Algorithmic fairness. In Aea papers and proceedings, Vol. 108. 22-27.

[19] Emily A Knapp and Lorraine T Dean. 2018. Consumer credit scores as a novel tool for identifying health in urban US neighborhoods. Annals of epidemiology 28, 10 (2018), 724-729.

[20] Leigh Matthews, Frédéric c, Debbie Martin, Sam, Luna, Cheb, Colin, Peter Dockx, Judith, S Judge, and et al. 2021. The 15 Most Sustainable Cryptocurrencies for 2021. https://www.leafscore.com/blog/the-9-most-sustainablecryptocurrencies-for-2021/

[21] Marcela S Melara, Aaron Blankstein, Joseph Bonneau, Edward W Felten, and Michael J Freedman. 2015. \{CONIKS\}: Bringing Key Transparency to End Users. In 24th \{USENIX\} Security Symposium (\{USENIX\} Security 15). 383-398.

[22] David Miller. 1995. On nationality. Clarendon Press.

[23] MOSIP. 2019. An open source platform on which national foundational IDs are built. https://www.mosip.io/about.php. (Accessed on 04/01/2021).

[24] Thomas W Murphy Jr. 2021. Energy and Human Ambitions on a Finite Planet. (2021).

[25] Eric Neumayer. 2010. Visa restrictions and bilateral travel. The professional geographer 62, 2 (2010), 171-181.

[26] Kimmo Nevalainen. 2018. Human Resource Demand Planning-tools and processes for visa processing of Ministry for Foreign Affairs of Finland. (2018)

[27] NSDL. [n.d.]. NSDL e-Governance Infrastructure Limited. https://www.egovnsdl.co.in/e-sign.html. (Accessed on 04/06/2021).

[28] United States Department of Homeland Security. 2020. Feature Article: S\&T SVIP Leverages Blockchain Interoperability to Support DHS | Homeland Security. https://www.dhs.gov/science-and-technology/news/2020/10/08/feature- article-st-svip-leverages-blockchain-interoperability-support-dhs. (Accessed on $04 / 06 / 2021$ )

[29] Govt. of India. [n.d.]. DigiLocker | Free, Secure, Flexible and easy-to-use application. https://digilocker.gov.in/. (Accessed on 04/06/2021).

[30] United States Department of State. 2012. Capitalizing on Visa Demand to Spur Economic Growth in the United States. https://travel.state.gov/content/travel/en/ us-visas/visa-information-resources/capitalize-on-visa-demand.html. (Accessed on $04 / 03 / 2021$ )

[31] Morgen E Peck. 2017. Blockchains: How they work and why they'll change the world. IEEE spectrum 54, 10 (2017), 26-35.

[32] Antoine Pécoud and Paul De Guchteneire. 2006. International migration, border controls and human rights: Assessing the relevance of a right to mobility. Fournal of Borderlands Studies 21, 1 (2006), 69-86.

[33] Harry Pettit. 2019. Elon Musk's SpaceX could cut London to New York flight to just 29 minutes with 'high-speed spacecraft'. https://www.thesun.co.uk/ tech/8689029/elon-musk-spacex-space-travel-london-new-york/. (Accessed on 04/01/2021).

[34] Bahamas Press. 2021. Public data compromised by hackers in the government's visa site. Government said not a word to the public. https://bahamaspress.com/public-data-compromised-by-hackers-in-thegovernments-visa-site-government-said-not-a-word-to-the-public/. (Accessed on $04 / 03 / 2021$ ).

[35] Barath Raghavan and Daniel Pargman. 2016. Refactoring society: systems complexity in an age of limits. In Proceedings of the Second Workshop on Computing within Limits. 1-7.

[36] Samar Sabie, Jay Chen, Azza Abouzied, Fatma Hashim, Harleen Kahlon, and Steve Easterbrook. 2017. Shelter dynamics in refugee and IDP camps: Customization, permanency, and opportunities. In Proceedings of the 2017 Workshop on Computing within Limits. 11-20.

[37] Sambhav Satija, Apurv Mehra, Sudheesh Singanamalla, Karan Grover, Muthian Sivathanu, Nishanth Chandran, Divya Gupta, and Satya Lokam. 2020. Blockene: A High-throughput Blockchain Over Mobile Devices. In 14th USENIX Symposium on Operating Systems Design and Implementation (OSDI 20). USENIX Association, 567-582. https://www.usenix.org/conference/osdi20/presentation/satija

[38] United States Visa Information Service. 2018. Visa Fees (English). https://www. ustraveldocs.com/no/no-niv-visafeeinfo.asp. (Accessed on 04/03/2021).

[39] Alan Sica. 2017. Debt to Society: Accounting for Life under Capitalism.

[40] Sudheesh Singanamalla, Esther Han Beol Jang, Richard Anderson, Tadayoshi Kohno, and Kurtis Heimerl. 2020. Accept the Risk and Continue: Measuring the Long Tail of Government https Adoption. In Proceedings of the ACM Internet Measurement Conference. 577-597.

[41] Manu Sporny, DC Burnett, D Longley, and G Kellogg. 2018. Verifiable credentials data model 1.0: Expressing verifiable information on the Web. s Draft 7 (2018).

[42] Bill Tomlinson. 2015. Toward a computational immigration assistant. First Monday (2015).

[43] Indre Žliobaitè. 2017. Measuring discrimination in algorithmic decision making. Data Mining and Knowledge Discovery 31, 4 (2017), 1060-1089. 